\title{
Determinação do índice da qualidade do aterro de resíduos do município de Goiânia/GO
}

O gerenciamento adequado dos resíduos sólidos urbanos (RSU) tem sido um dos principais desafios enfrentados pela administração pública, principalmente no que tange às questões ambientais. Dentre as formas de disposição dos resíduos, os aterros sanitários são considerados a mais adequada, porém, o funcionamento e a operacionalidade dos mesmos deixam a desejar em vários aspectos relacionados às exigências legais. Nesta perspectiva, o presente trabalho teve como objetivo avaliar a qualidade da disposição final dos resíduos sólidos no aterro sanitário do município de Goiânia/GO, através da aplicação do Índice de Qualidade de Aterros de Resíduos (IQR), metodologia proposta pela CETESB como forma de verificar a sustentabilidade deste ambiente. Observou-se, com base nos dados coletados, que $o$ aterro em estudo possui IQR de 2,2 pontos, sendo avaliado em condições inadequadas de funcionamento, em virtude dos vários aspectos operacionais, estruturais e locacionais irregulares que atestaram a insustentabilidade do local. Verificou-se que a metodologia aplicada pela CETESB para mensurar o IQR foi uma importante ferramenta para determinar possíveis melhorias a serem adotadas no aterro estudado, mostrando ser eficiente a sua aplicabilidade nos municípios e suas respectivas instalações para disposição final de resíduos sólidos.

Palavras-chave: Aterro sanitário; Resíduos sólidos urbanos; Indicadores de qualidade ambiental; IQR.

\section{Determination of the waste landfill quality index of the municipality of Goiânia/GO}

\begin{abstract}
The proper management of solid urban waste has been one of the main challenges faced by the public administration, especially with regard to environmental issues. Among the forms of waste disposal, landfills are considered the most appropriate, but their functioning and operability leave much to be desired in several aspects related to legal requirements. In this perspective, the present work aimed to evaluate the quality of the final disposal of solid waste in the waste landfill in the municipality of Goiânia/GO, through the application of the Quality Index of Waste Landfills (IQR), methodology proposed by CETESB, as a way to verify the sustainability of this environment. It was observed based on the collected data, that the landfill under study has an IQR of 2.2 points, being evaluated in inadequate operating conditions due to the various operational, structural and local irregular aspects, which attested to the unsustainability of the site. It was verified that the methodology applied by CETESB to measure the IQR was an important tool to determine possible improvements to be adopted in the landfill under study, showing to be efficient in its applicability to municipalities and their respective facilities for solid waste disposal.
\end{abstract}

Keywords: Sanitary landfill; Solid urban waste; Environmental quality indicators; IQR.

Topic: Engenharia Ambiental

Reviewed anonymously in the process of blind peer.

Rosana Gonçalves Barros (it)

Instituto Federal de Goiás, Brasil

http://lattes.cnpq.br/3009142457782923

http://orcid.org/0000-0003-4007-3450

rosana.ifg@gmail.com

Byanca Rodrigues Dourado (iD

Instituto Federal de Goiás, Brasil

http://lattes.cnpq.br/1769302023425833

http://orcid.org/0000-0001-7391-0599

byanca.eng@gmail.com

Viníciu Fagundes Bárbara (iD

Instituto Federal de Goiás, Brasil

http://lattes.cnpq.br/3052075493147161

http://orcid.org/0000-0001-9243-5543

viniciu.fagundes@gmail.com
Received: 14/03/2020

Approved: $20 / 04 / 2020$

\section{Referencing this:}

BARROS, R. G.; DOURADO, B. R.; BÁRBARA, V. F.. Determinação do índice da qualidade do aterro de resíduos do município de Goiânia/GO. Revista Ibero Americana de Ciências Ambientais, v.11, n.3, p.155-166, 2020. DOI: http://doi.org/10.6008/CBPC21796858.2020 .003 .0014 


\section{INTRODUÇÃO}

O acelerado processo de urbanização, aliado ao consumo crescente de produtos menos duráveis, e/ou descartáveis, provocou sensível aumento do volume e diversificação do lixo gerado e sua concentração espacial. Desse modo, o encargo de gerenciar o lixo tornou-se uma tarefa que demanda ações diferenciadas e articuladas, as quais devem ser incluídas entre as prioridades de todas as municipalidades (CEMPRE, 2018).

Segundo dados do Panorama de Resíduos Sólidos da Associação Brasileira de Empresas de Limpeza Pública e Resíduos Especiais (ABRELPE, 2017), a população brasileira gera, em média, aproximadamente 1 kg de resíduo por dia, valor considerado muito alto se comparado com a taxa de desenvolvimento do país. Mesmo com o sistema de políticas públicas e incentivos da parte do Governo Federal, 40,9\% de todo o resíduo gerado nacionalmente não tem o tratamento e nem a destinação ambientalmente adequada.

No Brasil, desde a criação da Política Nacional de Resíduos Sólidos (PNRS), o país discute a gestão adequada dos resíduos sólidos urbanos (RSU). Esta Lei defini como disposição final ambientalmente adequada, a distribuição ordenada de rejeitos em aterros, observando normas operacionais específicas, de modo a evitar danos ou riscos à saúde pública e à segurança, assim como minimizar os impactos ambientais adversos (BRASIL, 2010).

Apesar de todos os cuidados, até mesmo os aterros sanitários devidamente construídos seguindo as normativas são passíveis de contaminar o solo e a água, pois o revestimento desses locais pode apresentar falhas e, por isso, necessita ser monitorado (SIZIRICl et al., 2014). Além do monitoramento ambiental que contempla, dentre outros aspectos, análises de água subterrânea e lixiviado, nota-se a necessidade de critérios e parâmetros para avaliar a qualidade dos locais de disposição final de resíduos.

A partir da análise de instrumentos de Gestão Ambiental visando a qualificação dos sistemas de disposição final através de levantamentos e avaliações sobre as condições sanitárias dos locais de deposição final dos resíduos sólidos domiciliares, a Companhia de Tecnologia de Saneamento Ambiental do Estado de São Paulo (CETESB) desenvolveu, em 1997, o Índice de Qualidade de Aterro de Resíduos - (IQR). A partir de então, passou a aplicar e sistematizar as informações obtidas, de modo a compor o Inventário Estadual de Resíduos Sólidos Domiciliares, constituindo uma relevante ferramenta de Gestão Ambiental.

De acordo com Monteiro (2006), os índices são instrumentos que medem cada indicador, atribuindoIhe valores numéricos, ou são resultado da combinação de diversas variáveis ou parâmetros em um só valor, assumindo um peso relativo a cada componente do índice. Permitem observar e acompanhar a situação do meio ambiente, o impacto e as consequências dos processos de desenvolvimento sobre os recursos naturais, as funções ecológicas e as inter-relações entre os diferentes fatores do desenvolvimento.

Conforme expresso no Manual de Gerenciamento Integrado, o IQR é apenas exemplificativo, o que permite alterações (CEMPRE, 2018). O instrumento desenvolvido pela CETESB em 1997 é composto por 41 indicadores divididos em três macroconjuntos: características do local, infraestrutura implantada e condições operacionais. Esse índice é gerado através de um formulário, que, quando preenchido, permite alcançar uma nota que enquadra as instalações de disposição final de resíduos sólidos urbanos em três condições: 
inadequadas, controladas ou adequadas. Dessa maneira, permite estabelecer um critério único de avaliação nos municípios com vistas a desenvolver e aprimorar mecanismos de controle de poluição ambiental (CETESB, 1997).

Em 2012, a CETESB realizou mudanças na metodologia de classificação dos aterros de resíduos sólidos, onde introduziu itens sob o ponto de vista técnico e ambiental, tais como: adequabilidade do monitoramento geotécnico do aterro e ocorrência de episódio de queima de resíduos sólidos a céu aberto; análise da vida útil do aterro; ocorrência de restrições legais ao uso do solo. Além disso, alterou o enquadramento das instalações de disposição final de resíduos sólidos urbanos para duas condições: adequadas ou inadequadas (CETESB, 2012).

O uso desses índices de qualidade leva os tomadores de decisão (governos, técnicos, operadores) à adequação de aterros quanto à segurança ambiental e à legislação, à aplicação no desenvolvimento de projetos de continuidade do uso de aterros com redução dos impactos ambientais e ao fechamento dos aterros nos casos em que sejam exigidas tais medidas (ZAMORANO et al., 2005). Ainda, a aplicação dos índices serve para: organizar melhor os dados de um aterro com a formulação de um inventário, realizar análises e monitoramento ambiental com maior frequência, e, gerarem demandas na administração pública, voltadas para a Gestão Ambiental adequada dessas áreas.

Apesar do número de aterros sanitários em funcionamento no Estado de Goiás ser bastante reduzido, com apenas 16 municípios dispondo dessa prática de disposição final dos RSU, de acordo com o Plano Estadual de Resíduos Sólidos de Goiás (GOIÁS, 2017), a análise das condições de funcionamento desses locais representa uma contribuição à busca da sustentabilidade da gestão dos RSU. Nessa perspectiva, o presente trabalho teve como objetivo avaliar a qualidade da disposição final dos resíduos sólidos no aterro sanitário do Município de Goiânia/GO por intermédio da aplicação do IQR como forma de verificar a sustentabilidade deste ambiente.

\section{METODOLOGIA}

\section{Caracterização da área de estudo}

O aterro de resíduos sólidos em estudo (Figura 1), está localizado no Município de Goiânia, região central do estado de Goiás, Brasil, que atualmente possui uma população estimada de 1.516 .113 habitantes e uma área territorial de aproximadamente $730.000 \mathrm{Km}^{2}$ (IBGE, 2019). Situado entre as coordenadas geográficas de Latitude 1639'01.57"S e Longitude 4921'43.38”W, próximo à rodovia GO 060, no quilômetro 03, Setor Chácara São Joaquim, o Aterro Sanitário de Goiânia possui uma área de 451,033 m2 (Figura 1).

A área de disposição de resíduos sólidos foi implementada no ano de 1983, onde os resíduos eram dispostos diretamente no solo, sem qualquer controle. Somente em 1993 foram realizadas obras de impermeabilização, sendo o mesmo enquadrado como aterro sanitário (PMGIRS, 2016). De acordo com dados fornecidos pela Companhia de Urbanização de Goiânia COMURG, que opera o aterro, foram destinados no ano de 2018, cerca de 430 mil toneladas de resíduos sólidos para o local. 
É importante mencionar que o aterro em estudo não possui licença ambiental para funcionamento. Conforme preconiza a Resolução do Conselho Nacional do Meio Ambiente (CONAMA) no 01/ 1986, os aterros necessitam de licenciamento ambiental, por serem atividades modificadoras do meio ambiente e causadora de significativos impactos ambientais.

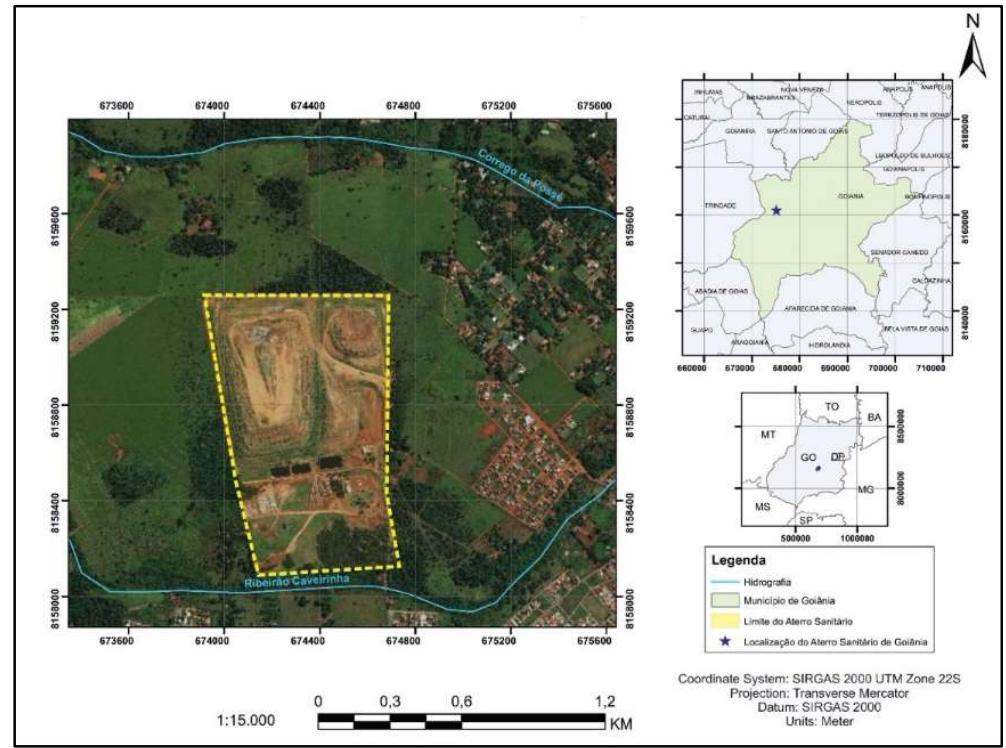

Figura 1: Localização do aterro sanitário de Goiânia, Goiás, Brasil.

\section{Determinação do índice de qualidade de resíduos (IQR)}

As informações para o cálculo do IQR foram coletadas nos meses de janeiro a novembro de 2019, por intermédio de visitas técnicas in loco ao aterro sanitário de Goiânia e por meio de pesquisa bibliográfica e documental, utilizando-se da metodologia adotada pela CETESB (2012), como agrega critérios de pontuação através de um formulário e é constituído por parâmetros relativos às características e condições operacionais, estruturais e locacionais. É importante ressaltar que o referido formulário foi preenchido por profissionais da área de saneamento, com acesso ao Aterro Sanitário de Goiânia.

Os parâmetros locacionais, estruturais e operacionais contemplados na planilha da CETESB (2012) são os seguintes: a) estrutura de apoio: portaria, balança e vigilância, isolamento físico e visual e acesso à frente de descargas; b) frente de trabalho: dimensões, compactação e recobrimento dos resíduos sólidos no referido local; c) taludes e bermas: dimensões e inclinações; cobertura de terra; proteção vegetal; afloramento de chorume; d) superfície superior: nivelamento da superfície e homogeneidade da cobertura; e) estrutura de proteção ambiental: impermeabilização do solo e qual a sua profundidade; drenagem e tratamento adequado do chorume; as condições da drenagem pluvial e dos gases; monitoramento geotécnico, das águas subterrâneas e gases; f) outras informações: presença de catadores, queima de resíduos sólidos, ocorrência de moscas e odores; presença de aves e outros animais; recebimento de resíduos não autorizados; recebimento de resíduos industriais; estruturas e procedimentos; g) característica da área: proximidade de núcleos habitacionais, proximidade de corpos de água, vida útil da área; restrições legais ao uso do solo.

O formulário do IQR é composto por três macroconjuntos. Para cada subitem que compõe o 
formulário atribui-se um valor, de acordo com as informações obtidas e características do aterro de resíduos. O somatório dos valores atribuídos gera subtotais para cada um dos macroconjuntos, totalizando a geração de três subtotais.

De acordo com a Equação 1, a soma desses subtotais divididos por dez gera o valor do IQR.

$$
\mathrm{IQR}=\frac{\text { Subtotal 1+Subtotal 2+Subtotal } 3}{10} \quad \text { (Equação 1) }
$$

Após a determinação do IQR (equação 1), os resultados encontrados são analisados e interpretados, para posterior enquadramento do aterro de resíduos sólidos em condições adequadas ou inadequadas, conforme o Quadro 1.

Quadro 1: Enquadramento das condições das instalações de tratamento e/ou disposição final de resíduos sólidos domiciliares em função dos índices IQR.

\begin{tabular}{|l|l|}
\hline IQR & AVALIAÇÃO \\
\hline 0,0 a 7,0 & Condições Inadequadas \\
\hline 7,1 a 10,0 & Condições Adequadas \\
\hline
\end{tabular}

Fonte: CETESB (2012).

É importante salientar que, para a caracterização do aterro tomou-se como referência a NBR 13.896 de 1997 (ABNT, 1997), que estabelece exigências mínimas para a localização de aterros e que leva em consideração: a topografia do terreno; os recursos hídricos; a distância de núcleos habitacionais; os critérios geológicos e pedológicos; a vegetação; as vias de acesso; o tamanho disponível; a vida útil e os custos.

\section{RESULTADOS E DISCUSSÃO}

O aterro de resíduos em estudo foi avaliado com base na metodologia proposta pela CETESB (2012), onde foram observados três macroconjuntos, sendo eles: aspectos estruturais (Quadro 2), operacionais (Quadro 3) e locacionais (Quadro 4).

\section{Caracterização dos aspectos estruturais do aterro de resíduos sólidos}

Dentro do primeiro macroconjunto foram avaliados 22 subitens que caracterizam os aspectos estruturais do Aterro Sanitário de Goiânia/GO (Quadro 2).

Quadro 2: Índice de Qualidade de Aterros de Resíduos (IQR) - pontuação referente ao macroconjunto 'aspectos estruturais'.

\begin{tabular}{|c|c|c|c|c|c|}
\hline ITEM & SU & ITEM & AVALIAÇÃO & PESO & PONTOS \\
\hline \multirow{8}{*}{ 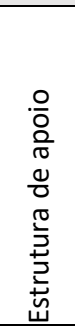 } & \multirow{2}{*}{1.} & \multirow{2}{*}{ Portaria, balança e vigilância } & Sim / suficiente & 2 & \multirow{2}{*}{2} \\
\hline & & & Não / insuficiente & 0 & \\
\hline & \multirow{2}{*}{2.} & \multirow{2}{*}{ Isolamento físico } & Sim / suficiente & 2 & \multirow{2}{*}{2} \\
\hline & & & Não / insuficiente & 0 & \\
\hline & \multirow{2}{*}{3.} & \multirow{2}{*}{ Isolamento visual } & Sim / suficiente & 2 & \multirow{2}{*}{2} \\
\hline & & & Não / insuficiente & 0 & \\
\hline & \multirow{2}{*}{4.} & \multirow{2}{*}{ Acesso à frente de descargas } & Sim / suficiente & 3 & \multirow{2}{*}{3} \\
\hline & & & Não / insuficiente & 0 & \\
\hline \multirow{6}{*}{ 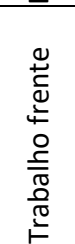 } & \multirow{2}{*}{5.} & \multirow{2}{*}{ Dimensões da frente de trabalho } & Adequadas & 5 & \multirow{2}{*}{5} \\
\hline & & & Inadequadas & 0 & \\
\hline & \multirow{2}{*}{6.} & \multirow{2}{*}{ Compactação dos resíduos } & Adequadas & 5 & \multirow{2}{*}{0} \\
\hline & & & Inadequadas & 0 & \\
\hline & \multirow{2}{*}{7.} & \multirow{2}{*}{ Recobrimento dos resíduos } & Adequadas & 5 & \multirow{2}{*}{0} \\
\hline & & & Inadequadas & 0 & \\
\hline
\end{tabular}




\begin{tabular}{|c|c|c|c|c|c|}
\hline ITEM & \multicolumn{2}{|c|}{ SUBITEM } & AVALIAÇÃO & PESO & PONTOS \\
\hline \multirow{8}{*}{ 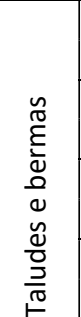 } & \multirow{2}{*}{8.} & \multirow{2}{*}{ Dimensões e inclinações } & Adequadas & 4 & \multirow{2}{*}{0} \\
\hline & & & Inadequadas & 0 & \\
\hline & \multirow{2}{*}{9.} & \multirow{2}{*}{ Cobertura de terra } & Adequadas & 3 & \multirow{2}{*}{3} \\
\hline & & & Inadequadas & 0 & \\
\hline & \multirow{2}{*}{10.} & \multirow{2}{*}{ Proteção vegetal } & Adequadas & 3 & \multirow[b]{2}{*}{3} \\
\hline & & & Inadequadas & 0 & \\
\hline & \multirow{2}{*}{11.} & \multirow{2}{*}{ Afloramento do chorume } & Não / raros & 4 & \multirow{2}{*}{0} \\
\hline & & & Sim / numerosos & 0 & \\
\hline \multirow{4}{*}{ 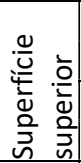 } & \multirow{2}{*}{12.} & \multirow{2}{*}{ Nivelamento da superfície } & Adequadas & 5 & \multirow{2}{*}{0} \\
\hline & & & Inadequadas & 0 & \\
\hline & \multirow{2}{*}{13.} & \multirow{2}{*}{ Homogeneidade da cobertura } & Sim & 5 & \multirow{2}{*}{0} \\
\hline & & & Não & 0 & \\
\hline & \multirow{2}{*}{14.} & \multirow{2}{*}{ Impermeabilização do solo } & Sim/adequada (ñ preencher item 15) & 10 & \multirow{2}{*}{0} \\
\hline & & & Não/inadequada (preencher item 15) & 0 & \\
\hline & \multirow{3}{*}{15.} & \multirow{3}{*}{ Profundidade lençol freático $(P) \times$ permeabilidade do solo $(k)$} & $\mathrm{P}>3 \mathrm{~m}, \mathrm{k}<10-6 \mathrm{~cm} / \mathrm{s}$ & 4 & \multirow{3}{*}{2} \\
\hline & & & $1<=\mathrm{p}<=3 \mathrm{~m} / \mathrm{K}<10-6 \mathrm{~cm} / \mathrm{s}$ & 2 & \\
\hline & & & Condição inadequada & 0 & \\
\hline & \multirow{2}{*}{16.} & \multirow{2}{*}{ Drenagem de chorume } & Sim / suficiente & 4 & \\
\hline & & & Não / insuficiente & 0 & 0 \\
\hline & 17 & & Sim / adequado & 4 & \\
\hline & $1 \%$ & Iratamento de chorume & Não / inadequado & 0 & 0 \\
\hline & & & Suficiente / desnecessária & 3 & 0 \\
\hline & 18. & Drenagem provisoria de aguas pluviais & Não / insuficiente & 0 & 0 \\
\hline$\stackrel{⿱ 乛}{c}$ & 19 & Drenagem definitiva de águas nluviais & Suficiente / desnecessária & 4 & 0 \\
\hline$\frac{0}{0}$ & 19. & Drenagem definitiva de aguas pluviais & Não / insuficiente & 0 & 0 \\
\hline$\frac{\varepsilon}{\sigma}$ & & & Suficiente / desnecessária & 4 & \\
\hline $2 \pi$ & 20. & Drenagem de gases & Não / insuficiente & 0 & 0 \\
\hline$\underset{0}{ \pm}$ & & & Adequado & 4 & \\
\hline 을 & 21. & Monitoramento de águas subterrâneas & Inadequado / insuficiente & 1 & 1 \\
\hline$\frac{\pi}{0}$ & & & Inexistente & 0 & \\
\hline$\stackrel{\frac{\pi}{7}}{\frac{1}{2}}$ & & & Suficiente / desnecessária & 4 & \\
\hline$\stackrel{\underline{Z}}{2}$ & 22. & Monitoramento geotécnico & Inadequado / insuficiente & 1 & 1 \\
\hline 䓌 & & & Inexistente & 0 & \\
\hline Somat & tória & dos 22 subitens (SUBTOTAL 1) & & & 24 \\
\hline
\end{tabular}

Verifica-se no Quadro 2, que dos 22 aspectos estruturais analisados no aterro sanitário de Goiânia/GO, apenas 6 estão em conformidade com a metodologia da CETESB (2012). De acordo com ReCESA (2008), a portaria deve manter um controle de acesso através do registro de dados de cada veículo (peso da tara, peso da carga, origem do material), além da emissão de recibos e documentos. No aterro sanitário de Goiânia/GO foi verificada a presença de portaria, balança e vigilância 24hs (Quadro 2 e Figuras 1 e 2).

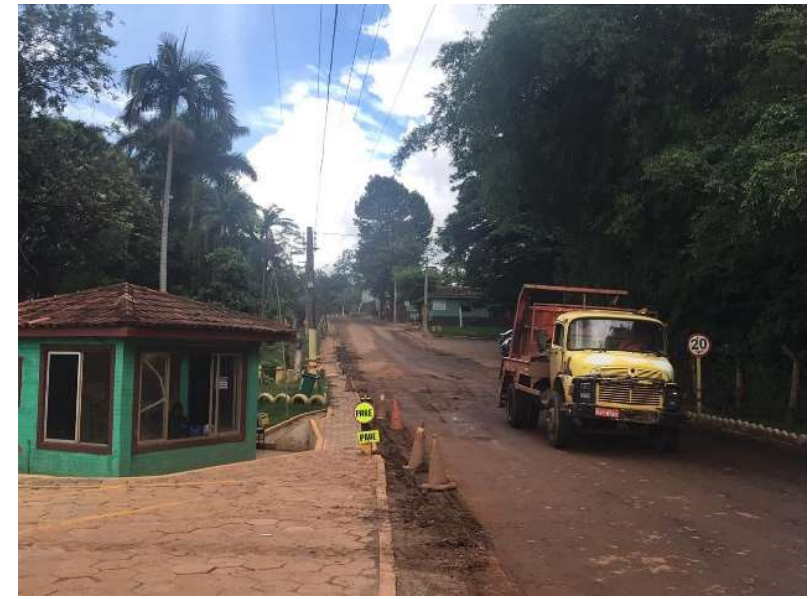

Figura 1: Portaria, vigilância e acesso as frentes de descarga do aterro sanitário de Goiânia/GO.

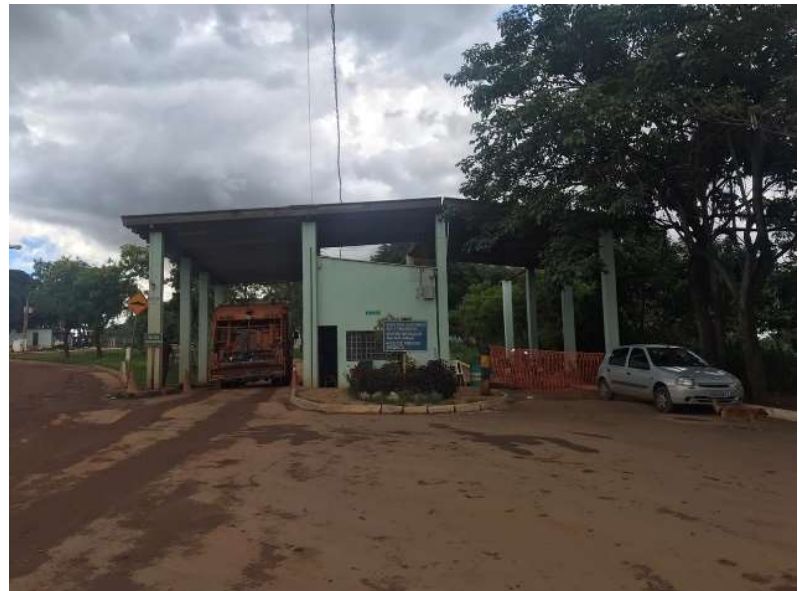

Figura 2: Balança do aterro sanitário de Goiânia/GO. 
Segundo a NBR 13.896 (1997), o isolamento físico caracteriza-se por cerca que circunde completamente a área em operação, construída de forma a impedir o acesso de pessoas estranhas e animais. O sistema tem a finalidade de utilizar a vegetação como barreira para suavizar a visualização do aterro e suas instalações, bem como diminuir a propagação de poeira e ruídos provocados pela movimentação de maquinas e maus odores provocados pelos gases no entorno do aterro (MANSOR et al., 2010).

Segundo a NBR 13.896 (1997) a utilização de cerca viva arbustiva ou arbórea ao redor da instalação tem como objetivo os aspectos referentes à vizinhança, a incidência de ventos além da estética. Verificou-se que o perímetro do aterro sanitário é cercado com arame para impedir o acesso de pessoas e animais e também apresenta um isolamento visual constituído por vegetação, para que além de questões estéticas, a vegetação possa atuar como um mitigador de mau odor (Quadro 2 e Figura3).

Segundo a NBR 13.896 (1997) os acessos devem ser executados de maneira a permitir o tráfego de máquinas e caminhões sob quaisquer condições climáticas. $\mathrm{O}$ acesso à frente de descargas do aterro sanitário está em condições satisfatórias, possui pavimentação, permitindo assim, que o trafego no local ocorra sem danos (Quadro 2 e Figura1).

Em relação ao subitem compactação e recobrimento dos resíduos sólidos, verificou-se que os procedimentos não são satisfatórios, pois o material utilizado para a cobertura era inadequado (resíduos da construção civil). Além disso, o maquinário utilizado para a atividade não era suficiente para espalhar e compactar os resíduos sólidos presentes na frente de trabalho (Quadro 2).

Segundo a Resolução do CONAMA 448/2012, os resíduos da construção civil não podem ser dispostos em aterros de resíduos sólidos urbanos, em áreas de 'bota fora', em encostas, corpos d'água, lotes vagos e em áreas protegidas por Lei. Os taludes existentes na área de estudo não possuíam uma padronização estabelecida, sendo os mesmos construídos com dimensões e inclinações diferenciadas, motivo pelo qual foram encontrados desmoronamentos na área (Quadro 2).

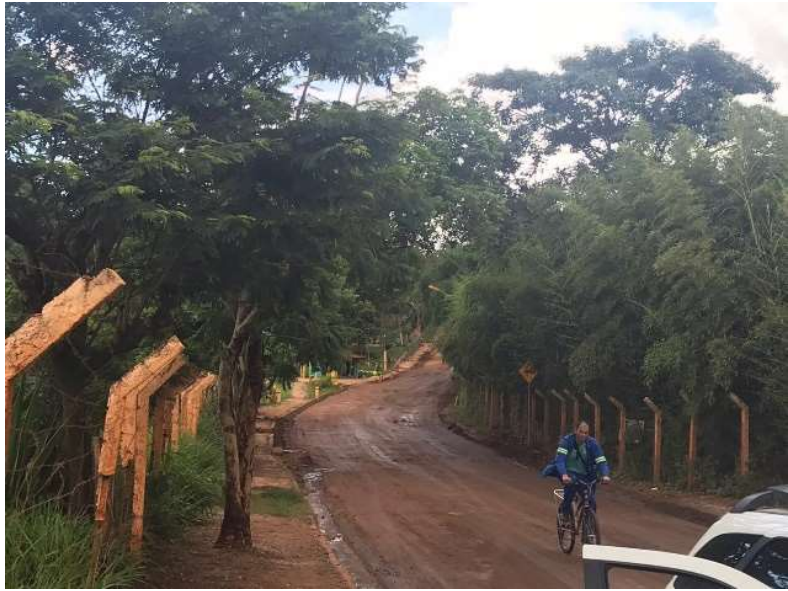

Figura 3: Isolamento físico e visual do aterro sanitário de Goiânia/GO.

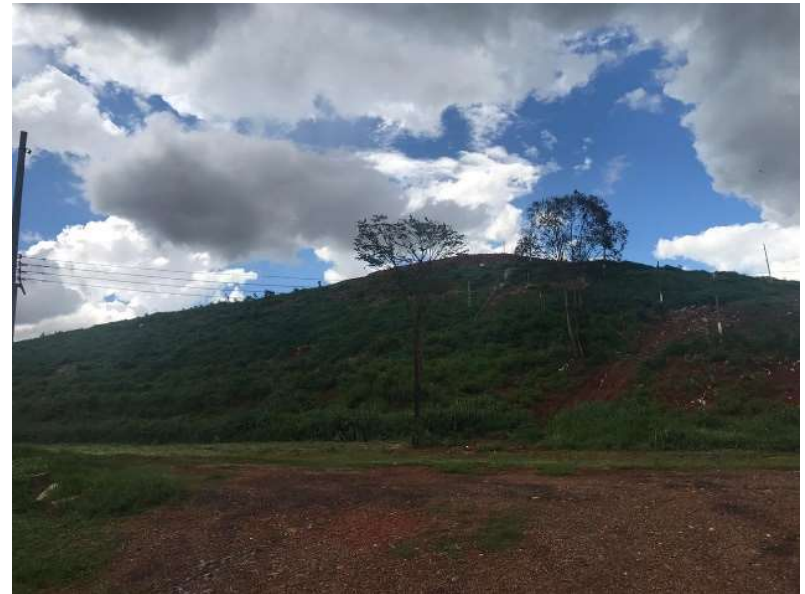

Figura 4: Cobertura vegetal nos taludes do aterro sanitário de Goiânia/GO.

A cobertura vegetal tem como objetivo conter os processos erosivos, evitando a exposição de materiais contaminantes e a propagação de vetores, além de formar uma barreira visual que limita a visualização do interior do aterro e suavizando seu aspecto estético (SOUZA, 2007). Como mostra a Figura 4 , 
observou-se a presença de cobertura vegetal em todo talude, estando assim, em conformidade com a metodologia proposta (Quadro 2). Durante as visitas técnicas, verificou-se que o nivelamento e a homogeneidade da cobertura de superfície encontravam-se em condições não satisfatórias, pois foram verificados resíduos sólidos misturados nas camadas de solo da cobertura (Quadro 2 e Figura 5).

Em relação à impermeabilização do solo, a NBR 13.896 (1997) especifica que a mesma pode ser realizada de duas formas: com camadas de materiais artificiais ou naturais, que impeçam ou reduzam substancialmente a infiltração no solo dos líquidos percolados. Na área do aterro em estudo, a impermeabilização foi realizada com material natural (argila), não havendo mantas plásticas.

De acordo com a Resolução CEMA 086/2013, são alternativas para o tratamento do chorume: recirculação (no próprio aterro); tratamento no local seguido de lançamento em corpo hídrico; tratamento por empresas terceirizadas; combinação dos métodos acima; demais tecnologias de tratamento validadas (PARANÁ, 2013).

Verificou-se o afloramento de chorume na área, principalmente na época de chuva. Isso se deve ao fato do sistema de drenagem das águas pluviais ser insuficiente, com apenas um dreno para tal finalidade (Quadro 2). Segundo Paula et al. (2019) no Aterro Sanitário de Goiânia não há tecnologia para o tratamento in loco do chorume, sendo o mesmo encaminhado para a ETE Hélio Seixo de Britto desde 2004. Com base nesta informação, e de acordo com a metodologia da CETESB (2012), o tratamento e a drenagem do chorume na área de estudo são inadequados (Quadro 2).

A drenagem de gases tem como objetivo a remoção dos gases gerados no interior do aterro de forma controlada. Estes são gerados a partir dos processos de decomposição da matéria orgânica presente nos resíduos sólidos urbanos (MANSOR et al., 2010). No aterro em estudo, o mecanismo de drenagem de gases é insuficiente, existindo apenas um dreno para toda a área de influência; além disso, o sistema não se encontra em funcionamento (Quadro 2).

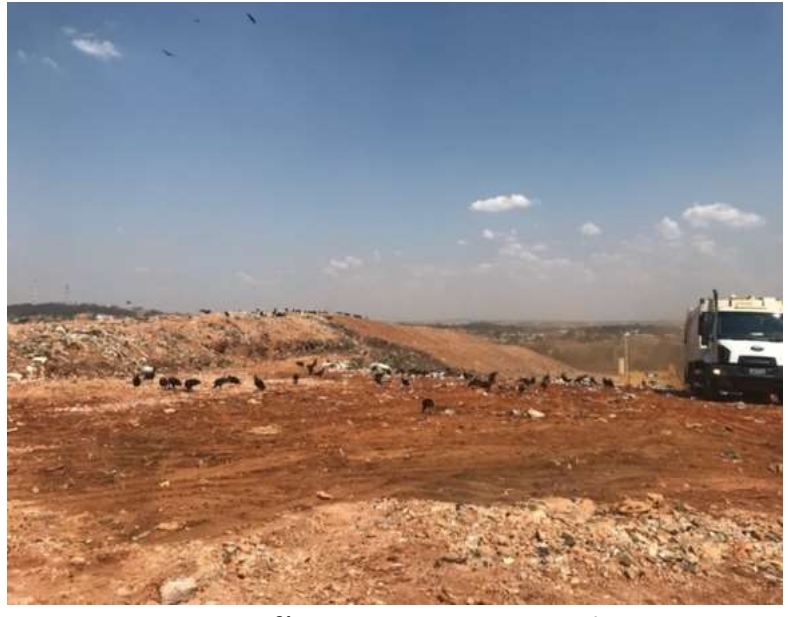

Figura 5: Superfície superior com nivelamento e homogeneidade em condições insatisfatórias.

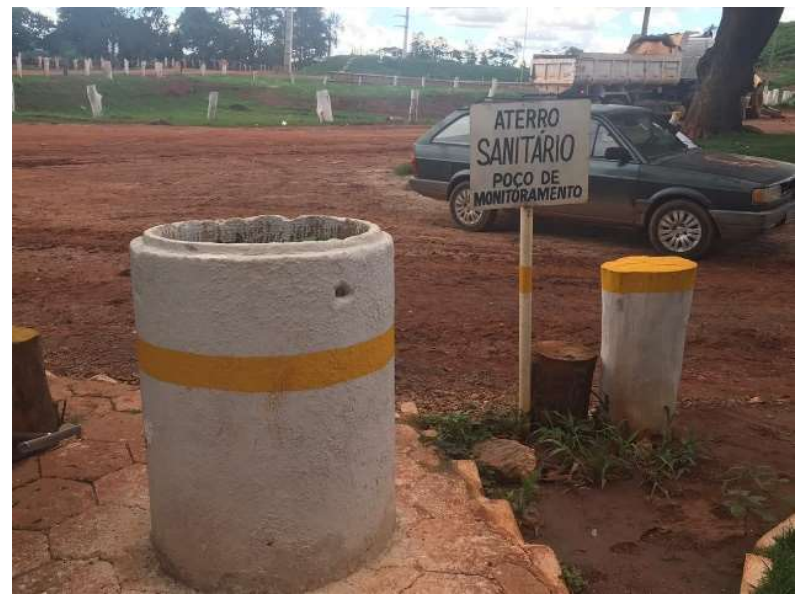

Figura 6: Poço de monitoramento.

De acordo com NBR 13.896 (1997) o monitoramento de águas subterrâneas tem como objetivo permitir uma avaliação de possíveis influências do líquido percolado, mantendo, desta maneira, a qualidade das águas do lençol freático. Observou-se na área, a existência de poços de monitoramento, porém, a 
frequência de realização deste procedimento é insuficiente, sendo realizado esporadicamente, somente executado de termos de cooperação com as universidades federais (Figura 6 e Quadro 2).

O monitoramento geotécnico é um sistema composto por: inspeção visual (indícios de erosão, trincas e fissuras na camada de cobertura ou qualquer outro sinal do movimento da massa de resíduos); deslocamentos verticais e horizontais (marcos superficiais e inclinômetro); e medidas de pressões de gases e líquidos no interior do maciço (piezômetros) (BRASIL, 2009). Na área, o monitoramento geotécnico também é realizado somente através de termos de cooperação, sendo classificado como insuficiente.

\section{Caracterização dos aspectos operacionais do aterro de resíduos sólidos}

Dentro do segundo macroconjunto, foram avaliados sete subitens que caracterizam os aspectos operacionais do Aterro Sanitário de Goiânia/GO (Quadro 3).

Quadro 3: Índice de Qualidade de Aterros de Resíduos (IQR) - pontuação referente ao macroconjunto 'aspectos operacionais'.

\begin{tabular}{|c|c|c|c|c|c|}
\hline ITEM & \multicolumn{2}{|c|}{ SUBITEM } & AVALIAÇÃO & PESO & PONTOS \\
\hline & \multirow{2}{*}{1.} & \multirow{2}{*}{ Presença de catadores } & Sim & 2 & \multirow{2}{*}{0} \\
\hline & & & Não & 0 & \\
\hline & \multirow{2}{*}{2.} & \multirow{2}{*}{ Queima de resíduos } & Sim & 2 & \multirow{2}{*}{0} \\
\hline & & & Não & 0 & \\
\hline & \multirow{2}{*}{3.} & \multirow{2}{*}{ Ocorrência de moscas e odores } & Sim & 2 & \multirow{2}{*}{2} \\
\hline & & & Não & 0 & \\
\hline \multirow{8}{*}{ 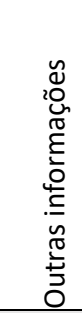 } & \multirow[t]{2}{*}{4.} & \multirow{2}{*}{ Presença de aves e animais } & Sim & 2 & \multirow{2}{*}{2} \\
\hline & & & Não & 0 & \\
\hline & \multirow{2}{*}{5.} & \multirow{2}{*}{ Recebimento de resíduos não autorizados } & Sim & 2 & \multirow{2}{*}{0} \\
\hline & & & Não & 0 & \\
\hline & \multirow{2}{*}{6.} & \multirow{2}{*}{ Recebimento de resíduos industriais } & Sim (preencher item 7) & \multirow[b]{2}{*}{-} & \multirow{2}{*}{-} \\
\hline & & & Não (não preencher item 7) & & \\
\hline & \multirow{2}{*}{7.} & \multirow{2}{*}{ Estruturas de procedimento } & Suficiente / adequado & 10 & \multirow[b]{2}{*}{ - } \\
\hline & & & Insuficiente / inadequado & 0 & \\
\hline Somat & $\mathrm{ac}$ & 7 subitens (SUBTOTAL 2) & & & 4 \\
\hline
\end{tabular}

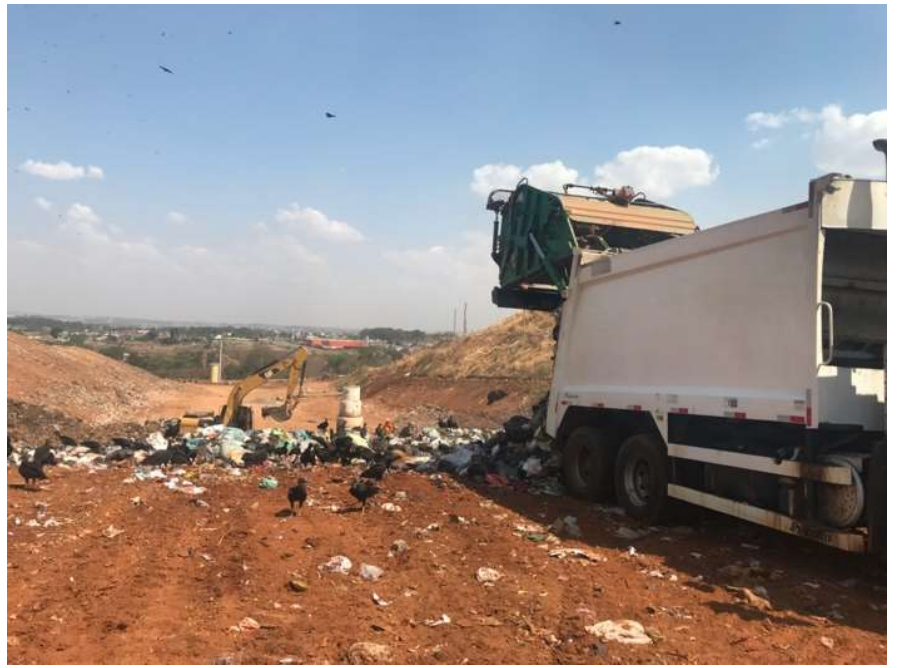

Figura 7: Presença de urubus na área do aterro sanitário de Goiânia/GO

Verifica-se no Quadro 3, que dos sete aspectos estruturais analisados no aterro de resíduos de Goiânia/GO, com a metodologia da CETESB (2012), sendo eles: presença de animais (urubus) e ocorrência de moscas e odores na área em estudo (Figura 3). Resultados semelhantes foram obtidos por Andrade et al. (2013) e Santos et al. (2012) que identificaram a presença de urubus nos aterros sanitários de Palmas/TO e 
Anápolis/GO, respectivamente. É importante mencionar que o subitem 6 não foi preenchido na planilha, pois o aterro em estudo não recebe resíduos industriais na área.

\section{Caracterização dos aspectos locacionais do aterro de resíduos sólidos}

Considerando o terceiro macroconjunto foram avaliados quatro subitens que caracterizam os aspectos estruturais do Aterro de Resíduos Sólidos de Goiânia/GO (Quadro 4). Verifica-se no Quadro 4, que todos os aspectos estruturais analisados no aterro sanitário de Goiânia/GO se encontram em inconformidade com a metodologia da CETESB (2012).

Quadro 4: Índice de Qualidade de Aterros de Resíduos (IQR) - pontuação referente ao macroconjunto 'aspectos locacionais'.

\begin{tabular}{|c|c|c|c|c|c|}
\hline ITEM & SU & TEM & AVALIAÇÃO & PESO & PONTOS \\
\hline \multirow{9}{*}{ 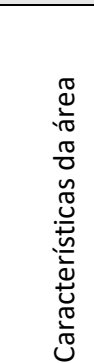 } & \multirow[t]{2}{*}{1.} & \multirow{2}{*}{ Proximidades de núcleos habitacionais } & $>=500 \mathrm{~m}$ & 2 & \multirow{2}{*}{0} \\
\hline & & & $<500 m$ & 0 & \\
\hline & \multirow[t]{2}{*}{2.} & \multirow{2}{*}{ Proximidade de corpos de água } & $>=200 \mathrm{~m}$ & 2 & \multirow{2}{*}{0} \\
\hline & & & $<200 \mathrm{~m}$ & 0 & \\
\hline & \multirow[t]{3}{*}{3.} & \multirow{3}{*}{ Vida útil da área } & $<=2$ anos & - & \multirow{3}{*}{-} \\
\hline & & & $2<x<=5$ anos & - & \\
\hline & & & $>5$ anos & $\mathrm{X}$ & \\
\hline & \multirow[t]{2}{*}{4.} & \multirow{2}{*}{ Restrições legais ao uso do solo } & Sim & $\mathrm{X}$ & \multirow{2}{*}{-} \\
\hline & & & Não & - & \\
\hline \multicolumn{5}{|c|}{ Somatório dos 4 subitens (SUBTOTAL 3) } & 0 \\
\hline
\end{tabular}

Conforme recomendação da NBR 13.896 (1997), a localização do aterro sanitário deve respeitar uma distância mínima de núcleos populacionais, onde esta distância, deve ser superior a 500 metros a partir do limite da área útil do aterro em relação ao núcleo populacional mais próximo. Verificou-se na área em estudo, que a distância dos núcleos habitacionais é menor que 500 metros (Quadro 4).

Em relação à proximidade de corpos d'água, a NBR 13.896 (1997) enfatiza que "o aterro sanitário deve ser localizado a uma distância mínima 200 metros de qualquer coleção hídrica ou curso de água". No local estudado, a distância encontrada foi de 200 metros do Córrego Caveirinha. Resultados contrastantes foram encontrados por Amaral et al. (2017), na mesma área de estudo, onde os mesmos verificaram uma distância maior que 200 metros do recurso hídrico.

\section{Determinação do índice de qualidade de resíduos (IQR)}

Após o preenchimento do formulário (Quadro 2, 3 e 4) foi possível calcular o IQR da área em estudo, conforme a equação abaixo:

$$
\mathrm{IQR}=\frac{24+4+0}{10}=2,8
$$

Através equação, obteve-se o valor do (IQR) de 2,8 pontos. De acordo com a metodologia da CETESB (2012), com este valor do IQR, tem-se que o Aterro Sanitário de Goiânia/GO apresenta condições inadequadas de funcionamento, com base nos aspectos estruturais, operacionais e locacionais, não podendo ser considerado como 'Aterro Sanitário'.

Alves (2015) utilizando a metodologia da CETESB de 2012, obteve o valor de IQR de 9,2 e 7,1 para os aterros de Cianorte/PR e Campo Mourão/PR, respectivamente, valores estes, classificados como adequados. 
Santos et al. (2012) aplicaram o IQR para avaliar o aterro de resíduos sólidos no Município de Anápolis-GO, e obtiveram o valor de 8,0 pontos, mostrando condições controladas de funcionamento, com base na metodologia da CETESB de 1997.

Pereira et al. (2017) verificaram que o IQR do aterro sanitário de Puxinanã/PB possui condições inadequadas de funcionamento, em virtude da ausência da cobertura diária dos resíduos ali dispostos; da inexistência de separação e triagem dos resíduos recicláveis e compostáveis; do acúmulo do lixiviado, gerando problemas ambientais para a população, bem como contribuindo para a insustentabilidade da gestão dos RSU.

Rosado et al. (2018) obtiveram o IQR de 6,23 pontos no aterro municipal de Paiçandu/PR, indicando condições adequadas, de acordo com a metodologia da CETESB (1997). Guerra et al. (2010) realizaram o diagnóstico do aterro de disposição de resíduos do Município de Taquarituba/SP, empregando a mesma metodologia, e obtiveram o IQR de 4,46 pontos, indicando condições inadequadas. Silva et al. (2016) também aplicaram o (IQR) no Município de Riacho Frio/PI, onde obtiveram o valor de 1,84 pontos, indicando condições inadequadas para o aterro.

\section{CONCLUSÕES}

Considerando a aplicação do IQR e com base no baixo valor obtido (IQR = 2,8 pontos), o aterro de resíduos de Goiânia/GO apresentou em condições inadequadas de funcionamento, em virtude dos seguintes aspectos: compactação e recobrimento dos resíduos sólidos; dimensões, inclinações, cobertura de terra e proteção vegetal dos taludes; nivelamento e homogeneidade da superfície superior; impermeabilidade do solo, drenagem de chorume, aguas pluviais e gases, monitoramento de águas subterrâneas e monitoramento geotécnico; ocorrência de moscas e odores e presença de urubus na área; proximidade de núcleos habitacionais e de corpos de água; entre outras irregularidades que atestam a insustentabilidade do local, comprometendo a gestão dos resíduos sólidos.

Observou-se que a metodologia aplicada pela CETESB para mensurar o IQR foi uma importante ferramenta para determinar possíveis melhorias a serem adotadas no aterro estudado, mostrando ser eficiente a sua aplicabilidade nos municípios e em suas respectivas instalações para disposição final de resíduos sólidos.

\section{REFERÊNCIAS}

ABNT. Associação Brasileira de Normas Técnicas. NBR 13.896. Fixa condições mínimas exigíveis para projetos, implantação e operação de aterros de resíduos sólidos não perigosos. Rio de Janeiro: ABNT, 1997.

ABRELPE. Associação Brasileira das Empresas de Limpeza Pública e Resíduos Especiais. Panorama dos Resíduos Sólidos no Brasil 2017. Rio de Janeiro, 2017.

ALVES, J. E. P.. Índice de Qualidade de Aterro de Resíduos: um estudo de caso nos municípios de Campo Mourão e Cianorte - Paraná. Monografia (Bacharelado em Engenharia
Civil) - Universidade Tecnológica Federal do Paraná, Campo Mourão, 2015.

AMARAL, N. K. A.; COSTA, R. D. F.; RIBEIRO, V. N.. Avaliação da área de disposição final dos resíduos sólidos no município de Goiânia/GO. Revista Ateliê Geográfico, Goiânia, v.11, n.2, p.205-222, 2017. DOI: http://doi.org/10.5216/ag.v11i2.39713

ANDRADE, C. C. T.; SERRA, J. C. V.; ANDRADE, A. B.. Aplicação de uma ferramenta de gestão ambiental de qualidade de aterros de resíduos sólidos urbanos. Revista de Ciências 
Ambientais, Canoas, v.7, n.2, 2013.

DOI: http://dx.doi.org/10.18316/1292

BRASIL. Lei. 12.305, de 2 de agosto de 2010. Institui a Política Nacional de Resíduos Sólidos. Brasília: DOU, 2010.

BRASIL. Programa Nacional de capacitação de gestores ambientais: Módulo específico licenciamento ambiental de estações de tratamento de esgoto e aterros sanitários. Brasília: MMA, 2009

CEMPRE. Lixo municipal: manual de gerenciamento integrado. 4 ed. São Paulo: CEMPRE, 2018.

CETESB. Companhia de Tecnologia de Saneamento Ambiental. Aterro sanitário: apostilas ambientais. São Paulo: CETESB, 1997.

CETESB. Companhia de Tecnologia de Saneamento Ambiental. Inventário Estadual de Resíduos Sólidos Domiciliares: Relatório de 2013. São Paulo: CETESB, 2012.

CONAMA. Conselho Nacional de Meio Ambiente. Resolução n. 448, de 19 de janeiro de 2012. Brasília: CONAMA, 2012.

GOIÂNIA. Plano Municipal de Gestão Integrada de Resíduos Sólidos. Goiânia: DOE, 2016.

GOIÁS. Plano Estadual de Resíduos Sólidos de Goiás. Goiânia: DOE, 2017.

GUERRA, F. A.; VIDAL, C. M. S.; SOUZA, J. B.. Proposta de melhoria de aterro de resíduos sólidos urbanos para um pequeno município. Revista Acadêmica de Ciências Agrárias e Ambientais, Curitiba, v.8, n.2, p.191-203, 2010. DOI: http://dx.doi.org/10.7213/cienciaanimal.v8i2.10844

IBGE. Instituto Brasileiro de Geografia e Estatística. Dados Gerais de Municípios. Rio de Janeiro: IBGE, 2019.

MANSOR, M. T. C.; CAMARÃO, T. C. R. COSTA; CAPELINI, M.; KOVACS, A.; FILET, M.; SANTOS, G. A.; SILVA, A. B.. Resíduos Sólidos. São Paulo: SMA, 2010.

MONTEIRO, A. E.. Índice de Qualidade de Aterros Industriais - IQRI. Dissertação (Mestrado em Engenharia Civil) - Universidade Federal do Rio de Janeiro, Rio de Janeiro, 2006
PAULA, G. L.; SANTOS, D. T.; DOURADO, R. B.; PEREIRA, R. P.. Avaliação do impacto em relação a caracterização do esgoto após o recebimento de chorume e efluente de fossas em uma ETE com tratamento quimicamente assistido. In: CONGRESSO BRASILEIRO DE ENGENHARIA SANITÁRIA E AMBIENTAL, 30. Anais. Natal: ABES, 2019.

PEREIRA, S. S.; CURI, C. R.. Aplicação do índice de qualidade de aterros de resíduos sólidos urbanos no Aterro Sanitário de Puxinanã/PB. Sustentabilidade em Debate, Brasília, v.8, n.1, p.108-124, 2017. DOI: http://doi.org/10.18472/SustDeb.v8n1.2017.21163

RECESA. Resíduos sólidos: projeto, operação e monitoramento de aterros sanitários: guia do profissional em treinamento: nível 2 / Ministério das Cidades. Secretaria Nacional de Saneamento Ambiental. Belo Horizonte: RECESA, 2008.

ROSADO, M. A.; AZENHA, D. T.; RICARDO, L. L.. Avaliação da condição do Aterro Municipal de Paiçandu/PR por meio do Método IQR. Monografia (Bacharelado em Engenharia Ambiental e Sanitária) - Centro Universitário de Maringá, Maringá, 2018.

SANTOS, A. L. F.; HARAGUCHI, M. T.; LEITÃO, G. C.. Índice de qualidade de aterro de resíduos (IQR), como subsídio para avaliar o sistema de disposição final do Município de Anápolis/GO. Scientia Plena, v.8, n.10, 2012.

SILVA, R. P. G.; AMORIM, M. F.; NOBRE, C. A.; COSTA, T. G. A.; ROCHA, I. L.. Aplicação do Índice de Qualidade de Aterros de Resíduos (IQR) em área de disposição de resíduos sólidos urbanos do Município de Riacho Frio/PI. Cadernos Cajuína, v.3, n.1, p.36-43, 2016.

SIZIRICI, B.; TANSEL, B.. Parametric fate and transport profiling for selective groundwater monitoring at closed landfills: a case study. Waste Management, v.38, n.1, p.263270, 2014.

DOI: http://doi.org/10.1016/j.wasman.2014.12.020

ZAMORANO, M.; GARRIDO, E.; MORENO, B.; PAOLINI, A.; RAMOS, A.. Environmental Diagnosis Methodology for Municipal Waste Landfills as a Tool for Planning and Decision Making Process. Sustainable Development and Planning II, v.1, p.545-554, 2005.

A CBPC - Companhia Brasileira de Produção Científica (CNPJ: 11.221.422/0001-03) detém os direitos materiais desta publicação. Os direitos referem-se à publicação do trabalho em qualquer parte do mundo, incluindo os direitos às renovações, expansões e disseminações da contribuição, bem como outros direitos subsidiários. Todos os trabalhos publicados eletronicamente poderão posteriormente ser publicados em coletâneas impressas sob coordenação da Sustenere Publishing, da Companhia Brasileira de Produção Científica e seus parceiros autorizados. Os (as) autores (as) preservam os direitos autorais, mas não têm permissão para a publicação da contribuição em outro meio, impresso ou digital, em português ou em tradução. 